\title{
STRESS CONDITIONS APPLIED TO THE INTERPRETATION OF TRANSLATION MACHINERY
}

\author{
JoAnna Smól, M. Astriab, Beata Dudzińska-Madej and T. Twardowski* \\ Institute of Bioorganic Chemistry, Polish Academy of Sciences \\ Noskowskiego 12/14, 61-704 Poznań, Poland
}

(Received: Jabuary15, 2000; accepted: January 29, 2000)

\begin{abstract}
Gene expression is regulated at the critical steps: a regulatory event occurs at the step which has a critical effect and is responsible for the limiting rate. Enzyme activity can be regulated at several different levels: transcriptional, translational or post-translational. In this review we describe (and illustrate with experimental data) plant stress which induces regulatory mechanisms at the translational and post-translational levels.

We found evidence for autorepression regulatory system of ferritin biosynthesis. Based on the knowledge of the molecular mechanism of regulation, we believe that ferritin protects the environment against heavy metal ions and supplements biological system(s) with iron.

The quinolizidine alkaloids' (QA) biosynthesis is lysine decarboxylase (LDC)-dependent. The available pool of LDC limits the conversion of lysine to cadaverine. The amount of LDC depends on transcriptional and translational efficiency. However, in the light of the presented data, we have evidence for a post-translational regulatory system, i.e. the activation of LDC from low to high activity enzyme through the conversion from higher to lower molecular weight form.

The plant protection system is very efficient. Understanding of the defence systems such as plant response to stress, should provide us with a possibility of applying this knowledge in practice and finding novel applications.
\end{abstract}

Keywords: Ferritin - Lupinus luteus - lysine decarboxylase - rRNA - translation

\section{INTRODUCTION}

There are two forms of stress in the plant world, i.e. biotic and abiotic. Translation of mRNA may be regulated by stability (e.g. rapid degradation of mRNA reduces its translatability), availability of messenger (e.g. mRNA engaged in specific ribonucleoprotein complex may not be available for translation), stimulation (e.g. changes of conformation or the presence of a specific effector regulate the speed and efficiency of mRNA reading). The (pre-existing) presence of translatable mRNA or the enhancement of its translatability makes the protein biosynthesis more rapid and more efficient. Usually, intensive synthesis of mRNA is associated with a signal from

*Corresponding author; E-mail: twardows@ibch.poznan.pl

Abbreviations: LDC - lysine decarboxylase, QA - quinolizidine alkaloids 
cytoplasm to the nucleus, which initiates the enhanced transcription of the corresponding gene. Consequently, we observe enhanced protein biosynthesis. Stressinduced enhanced biosynthesis of specific proteins represents a rapid response of the transcriptional and translational machinery to the specific conditions. Response to the specific conditions is faster and, consequently, more effective at the translation level.

Events naturally occurring during the development of the plant are often very similar to those induced by environmental conditions. Stress induced by chemical or physical factors can be considered as such a stimulus, similar to wound-induced changes.

We would like to focus on specific examples of stress induced protein biosynthesis in plant system, i.e. ferritin and LDC (lysine decarboxylase). These two proteins can be used as models for studying the regulatory mechanisms induced by stress conditions. For both of them we developed simple and efficient procedures of isolation and we performed general characterisation [published elsewhere: 2, 21, 48].

Stress-induced gene expression can be studied in many ways. One of them is the construction of cDNA libraries from the respective mRNA isolated from stressed tissue. An alternative approach is the study of a particular gene responsible for the biosynthesis of protein in response to wounding. The possibility of blocking of mRNA translation using antisens strategy is also taken into account. The interaction of regulatory fragments with antisens can be used for their identification.

\section{FERRITIN PROPERTIES - AS AN EXAMPLE OF ABIOTIC STRESS PROTEIN}

Ferritin should be discussed as an abiotic stress protein. In Fig. 1, the autorepression regulatory mechanism of ferritin biosynthesis is shown [according to 28, with minor modifications].

Ferritin is a protein responsible for the housekeeping of iron in the cell $[16,43]$. Iron is highly toxic - it hydrolyzes nucleic acids. However, it is also a necessary component for several enzymatic processes occurring within the biological systems. Ferritin consists of two subunits: the light one (MW 26,5 kDa) and the heavy one (MW $28 \mathrm{kDa}$ ) and the active molecule charged with iron has a molecular weight of about $450 \mathrm{kDa}[21,22,23]$. The subunits form a shell which surrounds up to 6000 divalent iron ions per a ferritin molecule [J. Smól - unpublished]. The smaller subunit has a lower molecular weight probably as a result of deletion of some (about 20) amino acids from the C-terminal end. Based on our sequence analysis, searching through the data base and testing by polyacrylamide gel electrophoresis, we think that in case of ferritin the subunits are not programmed by different mRNAs but they are a result of post-translational modification [38]. Ferritin biosynthesis is regulated at the transcriptional and translational levels [37, 38]. The autoregulatory mechanism at the translational level is dependent on iron concentration (mechanism of autorepression and derepression of mRNA specific for plant ferritin - shown in Table 1). It 
is evident from the literature that a conservatory regulatory structure iron responsive element (IRE) exists exclusively in animal systems [12, 14, 18, 19, 24, 33, 45]. IRE is localised upstream of the reading frame (UTR). This element is responsible for the regulation of ferritin biosynthesis in animal systems by interaction with cytosolic IRE - binding proteins (IRE - BP). This interaction depends on iron concentration in cells. Binding of these proteins by IRE leads to translation inhibition due to inhibition of translation initiation. However, the N-terminal sequences showed high simi-

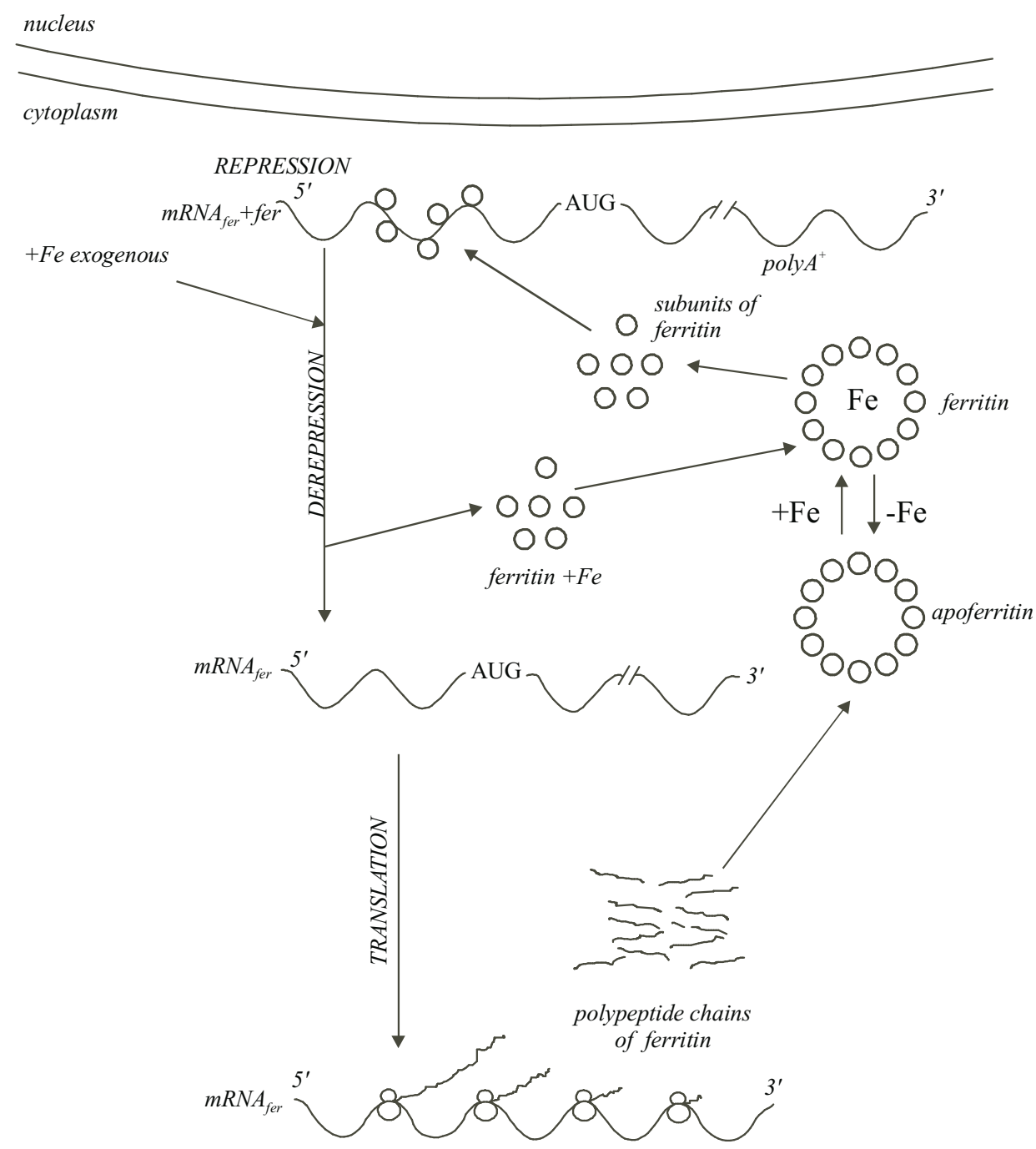

Fig. 1. A scheme of autorepression regulatory mechanism of ferritin' biosynthesis [28, with minor modifications] 
larity in plants, especially the sequences between the 101-160, and 210-300 amino acids $[37,38,46]$.

Having learned the molecular mechanism of plant ferritin biosynthesis we suggest two functions of this protein:

- protection of the environment against heavy metal ions;

- supplementing higher vertebrates with iron.

The first function offers a great potential for environmental protection. It turned out that ferritin is also able to protect plants against the oxidative damage. Deák et al. [6] showed that tobacco plants transformed by alfalfa ferritin cDNA gained the resistance to the oxidative damage caused by reactive oxygen forms. It is well known that iron has got a key role in free radicals generation (especially $\mathrm{OH}$ ). Therefore, ferritin as the agent controlling the concentration of free (potential toxic) iron plays the protective function against the oxidative effect which evokes necrotic symptoms $[6,7]$. Besides, overproduction of alfalfa ferritin in transgenic tobacco plants creates the tolerance to the damage caused by viral (for example tobacco necrosis virus) and fungal (Alternaria alternata, Botritis cinerea) infections [6]. The second function mentioned above could be of interest to pharmaceutical industry. The introduction of ferritin gene to rice in order to increase iron concentration in this plant is noteworthy of at this point $[13,15,35]$.

Based on the knowledge of ferritin properties we postulate that the plant system (for example yellow lupine) could be used for the protection of the environment and as a source of iron $\left(\mathrm{Fe}^{+2}\right)$ for higher vertebrates $[16,28]$. Biosynthesis of ferritin stimulated by abiotic stress (induced by the excess of metal ions) is followed by the binding of these ions by ferritin. In this way, stimulated synthesis of the ferritin may help protect the environment. In addition, plant ferritin rich in iron ions $\left(\mathrm{Fe}^{+2}\right)$ can also be a source of iron for anaemic higher organisms. The procedure of isolation of iron rich plant ferritin has already been submitted for patent application [36].

The knowledge of molecular properties of ferritin offers new opportunities of using plants with engineered metabolic regulations for the protection of environment and/or the supplying of the necessary component.

\section{LDC PROPERTIES - AS AN EXAMPLE OF BIOTIC STRESS PROTEIN}

Formation of the secondary metabolites, e.g. alkaloids, is one of the key issues for many aspects of plant biochemistry, such as food production and regulatory mechanism of many metabolic pathways. The understanding of biochemical changes occurring during the metabolic pathway is extremely important. Several factors affect alkaloid formation. They include the availability of components, stress conditions and the biological activity of key enzymes of metabolic pathway.

Lysine decarboxylase is a key enzyme in the quinolizidine alkaloid (QA) biosynthesis pathway, which takes place in many plants. LDC (lysine decarboxylase) can be regarded as a biotic stress protein. Some quinolizidine alkaloids, like sparteine and 


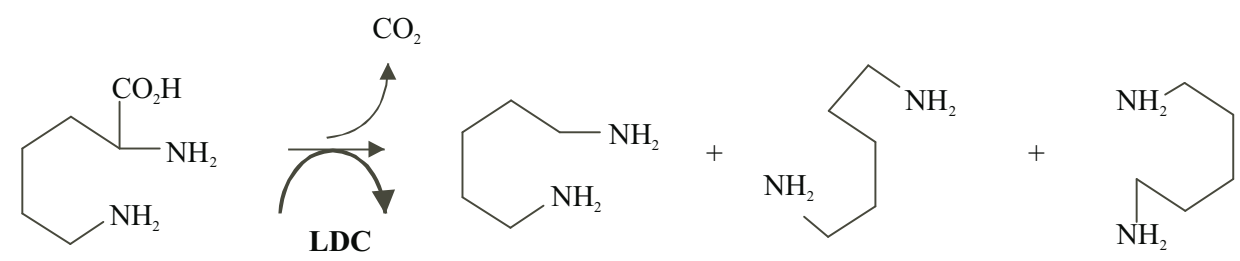

1.

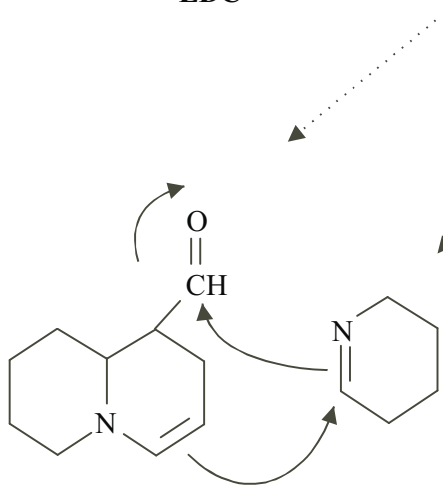

3.

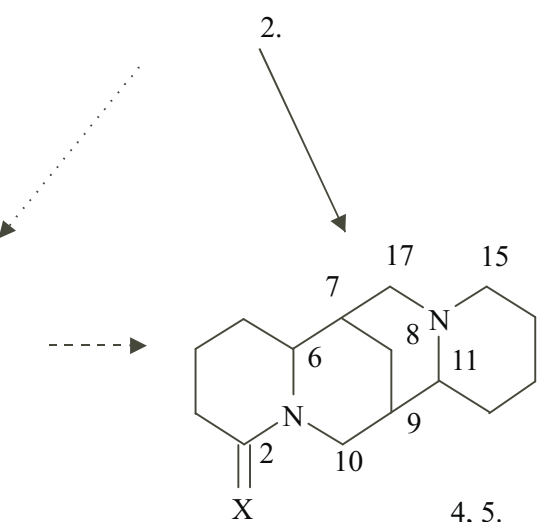

4. $\mathrm{X}=\mathrm{H}_{2}$ Sparteine 5. $\mathrm{X}=\mathrm{O}$ Lupanine

1. Lysine

2. Cadaverines

3. Intermediate compound

4. Sparteine

5. Lupanine

LDC = Lysine decarboxylase

Fig. 2. Transformation pathway of lysine via cadaverine to sparteine and lupanine. The decarboxylation of lysine (role of LDC) is indicated [32]

lupanine, are well-known allelochemicals. Lysine decarboxylase is responsible for decarboxylation of lysine during the biosynthesis pathway of these alkaloids in plant systems. In Fig. 2, biosynthesis of quinolizidine alkaloids and the function of LDC are shown [according to 32]. LDC activity is difficult to detect in any plant system. Besides, there are very few reports and no data on homogeneous plant LDC or sequences in data bank are available [17, 20, M. Astriab - unpublished]. In order to alter the alkaloid biosynthesis in plants the bacterial gene of LDC was used [32, $47,49]$.

There are at least two reasons for the difficulties in highly active LDC isolation: low specific activity of this enzyme and its instability [as reported by Wink: 47, 48]. LDC activity is a rate-limiting factor for biosynthesis of many alkaloids [9]. Overproduction of cadaverine may be the result of genetic manipulation and increased number of LDC gene copies and/or of the activation of the enzyme. The "low LDC level" observed by Fecker et al. [9] could be a misinterpretation: the level of LDC-protein was high but with low specific activity of LDC-enzyme. We can speculate about the possible mechanism(s): conversion of pre-enzyme to enzyme or 
activating function of chaperons [8]. Of course, the interpretation presented by Fecker that low transcription and/or translation level is due to the specificity and efficiency of codon usage in plant with bacterial system has to be taken into account as well.

\section{POST-TRANSLATIONAL REGULATION OF GENE EXPRESSION IN CASE OF STRESS}

Posttranscriptional regulation of the protein activity is possible at several distinct levels: by the activation of a specific messenger and de novo translation of this protein or by the activation of protein from inactive storage form [as is described in text books, e.g. 1 and in research papers 5, 10,11, 42]. For rapid translation, the available pool of temporarily inactive mRNA, which may be activated by the stress conditions, is of key importance. However, activation of a "silent" enzyme, which is in an inactive storage form, is another possibility of inducing plant response to stress. It is worth of notion that the latter is the fastest way and it requires minimum energy consumption. Evidently, the answer to the stress signal at the translational level is faster and requires less energy from the cell than at the transcriptional level. However, the latter has practically unlimited capacity in the production of new proteins.

There are numerous data concerning the transport of LDC molecules within the plant, from the green parts (leaves) to the roots and seeds [32, 48, 49 and references cited herein]. The increase of specific activity (followed by increased of total activity) of LDC may be a result of the de novo biosynthesis or of the removal of the endogenous inhibitor from the (protein - inhibitor) complex. In case of LDC, activation of the enzyme is strictly related to the association of the inhibitor. The chemical structure and biological function of this molecule have not yet been clarified. This association of the protein with a specific inhibitor is clearly a key element for the understanding of the biosynthesis pathway of alkaloids. Regulation through reversible modification offers unlimited possibilities for the functioning of the plant system (induction, repression, autorepression).

We propose a hypothesis that activation through the release of inhibitor occurs during the metabolic pathway of QA synthesis. The cut-out small polypeptide could play a vital role of a signalling peptide. The function of the small peptide in this case could be the activation of LDC through changing of the conformation from low to high activity. The correct conformation of LDC is dependent on the amino acid sequence but limited by information blocked by this peptide. This finding is highly similar to a well-established allosteric steric chaperones effects [7]. According to another hypothesis, the small peptide is covalently but transiently attached. As it is described by Plaxco and Gross [29] changing the conformation from unfolded to its native state is a key process in the regulatory mechanism of protein activity. In a few cases, examples of folded and unfolded enzymes are available [see ref. given therein, 29]. The folding process is usually viewed as a complicated, multistep process with sophisticated intermediates. Evidently, proteins are in a "dynamic milieu", 
which is sensitive to exogenous signals, induced by stress. The LDC case is an example of such situation.

It is commonly believed that in order to participate in the metabolic pathway, a secondary metabolite must be rapidly synthesised and transported to the target site. An endogenous fragment of a polypeptide may play the same function. However, it does not have to be de novo synthesised. Indeed, the answer to stress conditions may be much faster and much more efficient [31].

As far as ferritin is concerned, there are two different ways of post-transcriptional regulation:

- Autorepression mechanism; which is - in fact - the activation of inactive specific mRNA from the storage (protein-mRNA) complex by stress conditions. Translatability is limited by binding of the specific protein to ribonucleotide. This mechanism is well established in the literature [5].

- Hitherto unknown biological function of the different lengths of the polypeptide chains of the protein (the so-called heavy and light subunits) have not yet been recognised. According to our results, as it was earlier mentioned, a polypeptide is most probably reduced from the $\mathrm{C}$-terminal.

We found the following amino acid sequences for both subunits of ferritin: PNVSLARQNY and for the LDC: PNDXDDLLXIIE. Based on the determined N-terminal sequences we analyzed the sequence data bank and we found similarities. Based on these data it seems that in case of ferritine, the subunits are not programmed by different mRNAs but they are a result of post-translational modification. The smaller subunit has a lower molecular weight probably because of deletion of some (about 20) amino acids from the C-terminal end [38].

We believe that application of antisense strategy could be very useful and advantegous for solving the problem of how protein biosynthesis under stress conditions is regulated. There are following basic approaches for antisense strategy:

- triplex - attachment of the third oligomer to DNA helix,

- heteroduplex - formation of a complex between RNA and oligodeoxymer,

- ribozymes, oligoribomer with catalytic activity,

- aptamers, binding of oligomers to proteins.

- There are several variations and modifications of the basic concepts. For example: oligozymes, chemical modificationes, etc.

The most convincing evidence for the action of antisense oligomer is blocking of the action of enzymatic system, which is observed in in vitro biosynthesis of specific protein on mRNA. Antisense oligomer binding to the control region of mRNA inhibits protein biosynthesis at the translational level. This is exemplified by the inhibition of ferritin biosynthesis in vitro by unexpected conformational changes as the function of biological activity of the oligomer complementary to the IRE structure of ferritin mRNA [TT, preliminary, unpublished data]. The regulatory structure IRE is located in 5' UTR (untranslated region).

The mechanisms of the post-transcriptional regulatory steps are far from being understood. In case of both proteins, the shortening of the polypeptide chains still 
remains an open question. The characteristics of these molecules are the most intriguing questions. The elucidation of the nature of these phenomena, their mode of function, should help to unravel the mechanism(s) of translational control of biological activity of these two proteins.

\section{CONCLUSIONS}

The transcriptional regulatory mechanism provides an opportunity for the "production" of large amounts of a particular protein [4, 27]. However, being relatively slow, the transcription is in a way "delayed" in relation to the stress signal. The translational regulation allows the system to answer to the stress signal much faster, but with a limited capacity in terms of the amount of produced protein. Posttranslational regulation of the protein activity offers a possibility of an immediate answer to the signal. The aforementioned cases provide examples of specific translationally and post-translationally regulated gene expression. Contrary to the described specific regulations, the regulation at ribosomal level is an ideal candidate for a universal mechanism, unspecific for any given protein, at translational level. It is interesting that both described mechanisms are highly specific and similar. In a simplified way we may say that these are conversions from pre-enzymes to enzymes. We think that activation by the conditions is of key importance. The understanding of these processes is crucial for biotechnological applications.

\section{ACKNOWLEDGEMENT}

This project is supported within KBN grant 6P04B 03116

\section{REFERENCES}

1. Alberts, B. et al. (1998) Molecular Biology of the cell. Garland Publishing Inc., New York, 557-559.

2. Astriab, M. (1996) Izolacja oczyszczanie i właściwości dekarboksylazy lizynowej (LDC) z łubinu (L. Iuteus i L. albus) In: Frencel, K., Gulewicz, Z., Łubin, A. (eds) Kierunki badań i perspektywy użytkowe. Poznań, 204-211.

3. Barciszewski, J., Legocki, A. B. (1997) Two plant signalling peptides: systemin and ENOD 40. Acta B. Pol. 44, 795-802.

4. Bowless, D. J. (1990) Defence related proteins in higher plants. Ann. Rev. Biochem. 59, 873-907.

5. Briat, J. F., Lobreaux, S. (1997) Iron transport and storage in plants. Trends in Plant Science 2, 187-193.

6. Deák, M. et al. (1999) Plants ectopically expressing the iron-binding protein, ferritin, are tolerant to oxidative damage and pathogens. Nat. Biotech. 17, 192-196.

7. Elia, G. et al. (1999) Induction of ferritin and heat shock proteins by prostaglandin $A_{1}$ in human monocytes. Eur. J. Biochem. 264, 736-745.

8. Ellis, E. J. (1998) Steric chaperones. TIBS 23, 43-45.

9. Fecker, L. F., Rugenhagen, C., Berlin, J. (1993) Increased production of cadaverine and anabasine in hairy root cultures of Nicotine tabacum expressing a bacterial lysine decarboxylase gene. Plant Mol. Biol. 23, 11-21. 
10. Fobis-Loisy, L., Aussel, L., Briat, J. F. (1996) Post-transcriptional regulation of plant ferritin accumulation in response to iron as observed in the maize mutant ys1. FEBS Lett. 397, 149-154.

11. Fobis-Loisy, L. et al. (1995) Structure and C-differential expression of two maize ferritin genes in response to iron and abscisic acid. Eur. J. Biochem. 231, 609-619.

12. Gdaniec, Z., Sierzputowska-Gracz, H., Theil, E. C. (1998) Iron regulatory element and internal loop bulge structure for ferritin mRNA studied by cobald(III) hexamine bilding, molecular modeling, and NMR spectroscopy. Biochemistry 37, 1505-1512.

13. Goto, F. et al. (1999) Iron fortification of rice seed by the soybean fertitin. Nature Biotechnology 17, 282-286.

14. Gray, N., Hentze, M. (1994) Iron regulatory protein prevents binding of the 43s. Translation pre-initiation complex to ferritin and eALAs mRNA. EMBO J. 13, 3882-3891.

15. Gura, T. (1999) New genes boots rice nutrients. Science 285, 994-995.

16. Harison, P. M., Arosio, P. (1996) The ferritin: molecular properties, iron storage, function and cellular regulation. Biochim. Biophys. Acta 31, 161-203.

17. Herminghaus, S. et al. (1991) Expression of bacterial lysine decarboxylase gene and transport of the protein into chloroplasts of transgenic tobacco. Plant Mol. Biol. 17, 475-486.

18. Jaffrey, S. R. et al. (1993) The interaction between the iron-responsive element binding protein and its cognate RNA is highly depend upon both RNA sequence and structure. Nucleic Acids Res. 21, 4627-4631.

19. Kikinis, Z. et al. (1995) Role of RNA secondary structure of the iron-responsive element in translational regulation of ferritin synthesis. Nucleic Acids Res. 23, 4190-4195.

20. Kim, H. S., Kim, B. H., Cho, Y. D. (1998) Purification and characterisation of monomeric lysine decarboxylase from soybean (Glicine max) axes. Arch. Biochem. Biophys. 354, 40-46.

21. Korcz, A., Twardowski, T. (1992a) Lupin ferritin: purification and characterization, biosynthesis and regulation of in vitro synthesis in plant system. J. Plant Physiol. 141, 75-81.

22. Korcz, A., Twardowski, T. (1992b) The effect of selected heavy metal ions on wheat germ protective function of plant ferritin. Acta Physiol. Plant. 14, 185-190.

23. Kożuch, J. et al. (1997) Analysis of ferritin-type proteins in the hepatopancreas of Baltic blue mussel (Mytilus bossulus). Oceanologia 39, 157-162.

24. Leibold, E., Laudano, A., Yang, Yu (1990) Structural requirements of iron-responsive elements for binding of the protein involved in both transferrin receptor and ferritin mRNA post-tanscriptional regulation. Nucleic Acids Res. 18, 1819-1824.

25. Lescure, A. M., Massenet, O., Briet, J. F. (1990) Purification and characterization of an iron-induced ferritin from soybean (Glycine maz) cell suspensions. Biochem. J. 272, 145-150.

26. Lescure, A. M. et al. (1991) Fertitin gene transcription is regulated by iron in soybean cell cultures. Proc. Natl. Acad. Sci. USA 88, 8222-8226.

27. Lobreaux, S., Massent, O., Briat, J. F. (1992) Iron induces ferritin synthesis in maize plantlets. Plant Mol. Biol. 19, 563-575.

28. Munro, H. N., Linder, M. C. (1978) Ferritin: structure, biosynthesis and role in iron metabolism. Physiol. Rev. 2, 317-396.

29. Plaxco, K., Gross, M. (1997) The importance of being unfolded. Nature 386, 657-658.

30. Ragland, M. et al. (1990) Evidence for conservation of ferritin sequences among plants and animals and for transit peptide in soybean. J. Biol. Chem. 265, 18339-18344.

31. Rhodes, M. J. C. (1994) Physiological role for secondary metabolites in plants, some progress, many outstanding problems. Plant Mol. Biol. 24, 1-20.

32. Schoofs, G., Teichmann, S., Hartmann, T., Wink, M. (1983) Lysine decarboxylase in plants and its integration in quinolizidine alkaloid biosynthesis. Phytochemistry 22, 65-69.

33. Sierzputowska-Gracz, H., McKenzie, R. A., Theil, E. C. (1995) The importance of a single G in the hairpin loop of the iron responsive element (IRE) in ferritin mRNA for structure: an NMR spectroscopy study. Nucleic Acids Res. 23, 146-153.

34. Smól, J. (1996) Porównanie właściwości molekularnych ferrytyny wyizolowanej z łubinu żółtego (Lupinus luteus) i szarłatu szorstkiego (Amaranthus retroflexus). In: Frencel, Gulewicz Lubin: 
kierunki badań i perspektywy użytkowe. Postępy w badaniach łubinu, Polskie Towarzystwo Lubinowe - ICHB PAN Poznań, pp. 212-218.

35. Smól, J. (1999) Ferrytyna-ekwiwalentem żelaza w zapobieganiu i leczeniu anemii. Biotechnologia 3.

36. Smól, J., Twardowski, T. (1997) Sposób otrzymywania ferrytyny roślinnej (patent application submitted).

37. Smól, J., Twardowski, T. (1998) Ferrytyna-specyficzne białko ochronne. Postępy Biologii Komórki $25,511-524$.

38. Smól, J., Twardowski, T. (1999) Properties of lupin ferritin and regulatory mechanism of its biosynthesis. Biologia 54, 307-311.

39. Theil, E. C. (1987) Ferritin structure, gene regulation and cellular function in animals, plants and microorganisms. Annu. Rev. Biochem. 56, 289-315.

40. Theil, E. C. (1990) Ferritin mRNA translation, structure and gene transcription during development of animals and plants. Enzyme 44, 68-82.

41. Theil, E. C., Sayers, D. (1989) Iron core formation in ferritin. Basic Life Sci. 51, 161-167.

42. Van Wuytswinkel, O., Briat, J. F. (1995) Conformational changes and in vitro core - formation modifications induced by site - directed mutagenesis of the specific N-terminal of pea seed ferritin. Biochem. J. 305, 959-965.

43. Van Wuytswinkel, O. et al. (1998) Iron homeostasis alternation in transgenic tobacco overexpresing ferritin. Plant J. 17, 93-97.

44. Waldo, G. S. et al. (1995) Formation of the ferritin iron mineral occurs in plastids. Plant Physiol. 109, 797-802.

45. Wang, Y. H., Sczekan, S. R., Theil, E. C. (1990) Structure of the $5^{\prime}$ untranslated region of ferritin mRNA studied in solution. Nucleic Acid Res. 18, 4463-4468.

46. Wardrop, A. J., Wicks, R. E., Entsch, B. (1999) Occurrence and expression of members of the ferritin gene family in cowpeas. Biochem. J. 337, 523-530.

47. Wink, M., Hartmann, T. (1979) Cadaverine-pyruvate transamination: the principal step of enzymatic quinolizidine alkaloid biosynthesis in Lupinus polyphyllus cell suspension cultures. FEBS Lett. $101,343-346$.

48. Wink, M., Hartmann, T. (1982) Localization of the enzymes of quinolizidine alkaloid biosynthesis in leaf chloroplasts of Lupinus polyphyllus. Plant Physiol. 70, 74-77.

49. Wink, M., Hartmann, T., Schiebel, H. M. (1979) A model mechanism for the enzymatic synthesis of lupin alkaloids. Z. Naturforsch. 34, 704-708. 